\title{
História em quadrinhos: reflexões metodológicas ${ }^{1}$
}

\section{Comics: metholological reflections}

\author{
Lic. Henrique Denis Lucas \\ Universidade Federal de Santa Maria (Brasil) \\ henriquedlucas@gmail.com \\ Dra. Rosane Rosa \\ Universidade Federal de Santa Maria (Brasil) \\ rosanerosar@gmail.com \\ Cristini Fernandes \\ Universidade Federal de Santa Maria (Brasil) \\ cristinigaia@gmail.com
}

Recibido: 30 de julio de 2013

Aceptado y Publicado: 5 de octubre de 2013

\section{Resumen}

Este artigo apresenta uma proposta educomunicacional de formação em histórias em quadrinhos à alunos e professores do ensino fundamental de Escolas Públicas da cidade de Santa Maria (RS - Brasil). O objetivo é refletir sobre o potencial das histórias em quadrinhos como dispositivo pedagógico com potencial para qualificar o processo de aprendizagem e o desenvolvimento do protagonismo juvenil. Para tanto, nos apoiaremos em uma pesquisa bibliográfica por meio de autores que estudam a temática sob a perspectiva da educomunicação. As atividades propostas são um compilado de atividades já utilizadas em sala de aula por estes estudiosos. O trabalho poderá servir como guia para interessados em ministrar oficinas do mesmo gênero. $O$ objetivo do estudo é servir de facilitador para a capacitação de multiplicadores de conhecimento de histórias em quadrinhos para fins educativos.

\footnotetext{
1 Artículo producto de una Ponencia presentada en el VI Encuentro Panamericano de Comunicación COM PANAM 2013 celebrado la Escuela de Ciencias de la Información de la Universidad Nacional de Córdoba (Argentina), durante los días 5, 6 y 7 de junio de 2013.
} 


\section{Abstract}

This paper presents a proposal of educommunication of training in comics for elementary school students and teachers of the Public Schools in the city of Santa Maria (RS-Brazil). It has as objective to reflect about the potential of comics as a pedagogical tool able to enhance the learning process and the youth engagement. Therefore, this study was supported by a bibliographic research on authors that study this thematic on an educommunication perspective. The proposed activities are a collection of activities which were already used by those academics in classrooms. This work can serve as a guide for people interested in holding workshops on the theme. The objective of this study is to serve as a facilitator for the training of knowledge multipliers of comics with educational purposes.

Palavras-chave: Histórias em quadrinhos; Educomunicação; Metodologia; Aprendizagem.

Key Words: Comics; Educommunication; Methodology; Learning.

\section{Introdução}

O presente estudo apresenta uma reflexão sobre um método para a formação em histórias em quadrinhos à alunos e professores de escolas públicas da cidade de Santa Maria, estado do Rio Grande do Sul, no Brasil. Esta proposta está inserida em um programa maior intitulado Educomunicação e Cidadania Comunicativa, desenvolvido pela Universidade Federal de Santa Maria e financiado em 2011 e 2012 pela Coordenação de Aperfeiçoamento de Pessoal de Nível Superior (CAPES) e em 2013 pelo Ministério da Educação (MEC). O Programa objetiva democratizar a comunicação como um direito humano e contribuir para qualificação do ensino público. Para tanto, utiliza a metodologia de projetos educomunicativos que consiste em uma proposta pedagógica através dos meios de comunicação comerciais e alternativos e as tecnologias de informação e comunicação a serviço da educação.

A atuação se dá em forma de uma série de ações educomunicacionais, articuladas no formato de oficinas e cursos teórico-práticos que possibilitam o letramento midiático e o empoderamento comunicacional a professores e alunos de escolas. Além disso, visa integrar a comunicação como uma ferramenta interdisciplinar capaz de estimular a aprendizagem dos sujeitos e a sua participação na escola e na comunidade; 
desenvolver habilidades comunicacionais voltadas para a leitura crítica, a escrita e a pesquisa; estimular a criação de produtos midiáticos e a apropriação de diferentes linguagens que contribuam para a conscientização e a participação educacional, social e política; proporcionar um espaço de exercício da cidadania comunicativa. O Programa esta inserido no macro campo Comunicação e Uso das Mídias na Educação, da Política Pública Federal Mais Educação.

O presente artigo foca sua reflexão no processo metodológico da oficina de histórias em quadrinhos, ministrada aos alunos e professores das escolas públicas participantes do programa. Tais escolas apresentam baixo nível de IDEB (Índice de Desenvolvimento da Educação Básica). A oficina contempla uma média de oito encontros, nos quais aborda-se a história dos quadrinhos, suas características, a forma de construção das narrativas e dos sentidos e a interação entre elementos verbais e não-verbais, textuais e sígnicos.

Essa práxis segue os princípios educomunicativos, pois visa potencializar o processo participativo de aprendizagem por meio do uso de diferentes linguagens e dispositivos midiáticos. Assim, propõe-se a inserção das histórias em quadrinhos como dispositivo educacional, que possa ser utilizada em oficinas que se fundamentem e se foquem no aprendizado desta linguagem para posterior uso inter/transdisciplinar com os conteúdos programáticos das disciplinas do PCN (Parâmetros Curriculares Nacionais).

\section{Educomunicação}

Todo o ser humano tem direito de se comunicar e de expressar suas opiniões para a sociedade, e a comunicação deve contribuir para o exercício de uma cidadania comunicativa. No entanto, o acesso a produção de conteúdo informacional para os veículos de comunicação de massa é restrito quase que apenas às grandes corporações legitimadas pela sociedade de maneira hegemônica. Partindo deste diagnóstico e da necessidade de democratizar o acesso a comunicação como um direito humano, torna-se relevante refletir sobre essa realidade em uma perspectiva educomunicacional.

A Educomunicação se estabelece da união entre duas áreas, comunicação e educação, que juntas, buscam a formação de um sujeito que conheça seus direitos e responsabilidades perante a sociedade e faça uso disto para mudar a sua realidade e a de sua comunidade, pois "cidadania é o direito reservado a todas as pessoas de se inserir na sociedade de maneira participativa e não-alienada" (Projeto Nossa Mídia [PNM], s.d., p. 16) 
A proposta-chave da Educomunicação é "educar através da comunicação, comunicar através da educação" (PNM, s.d., p. 12). Desta forma, quando um jovem aprende a produzir uma história em quadrinhos, por exemplo, sua educação cidadã irá transparecer no produto, e este, pela aproximação da informação à sua realidade, será valorizado pelas pessoas da comunidade, transformando-a:

A proposta principal é refletir sobre como o profissional de comunicação pode contribuir para melhorar os processos educativos em geral e, em contrapartida, como os educadores podem trabalhar melhor com os meios de comunicação. Não é somente uma questão de escola, de prédio ou política pública - é algo do nível da sensibilidade dos sujeitos. (PNM, s.d., p.12)

O papel social dos meios de comunicação deve ser debatido criticamente por todas as camadas da sociedade, e é de suma importância que o educomunicador fomente esse debate, nos ambientes formais e informais, com o intuito de educar para a mídia, educar por meio da mídia e educar com a mídia.

A emancipação social se dá quando o sujeito apropria-se de uma visão crítica e política da mídia e da sociedade e se estabelece como cidadão. Compreender as funções culturais, políticas e sociais dos meios de comunicação possibilita que o sujeito desenvolva essa criticidade e produza seus próprios conteúdos de comunicação como dispositivos para este empoderamento. Desta forma, o cidadão produtor e consumidor equaliza as funções das mídias na sociedade,

A prática educomunicativa consiste, principalmente, em promover a educação, a reflexão e o pensamento humanista e crítico através do estudo e da produção de meios de comunicação como alavanca para educar e construir uma sociedade mais humanizadora. (PNM, s.d., p. 15)

Neste cenário, a proposta da Educomunicação se expande por meio de multiplicadores dessa práxis. São agentes sociais que compartilham suas experiências e competências, mas que também aprendem com a troca. É um processo de construção coletiva do conhecimento.

\section{Breve histórico das HQs educativas}

As primeiras Histórias em Quadrinhos tiveram seu início conjuntamente com o a formação das primeiras civilizações, na Pré-História, com as pinturas rupestres feitas nas paredes das cavernas. Os desenhos mostravam como era o dia-a-dia das tribos, suas caçadas e seus feitos. Mas isso era produzido utilizando-se de uma característica 
muito peculiar às HQs: a sequencialidade. Os desenhos primitivos não possuíam exatamente as mesmas qualidades e características que a atual Arte Sequencial, no entanto, já eram uma forma de narrativa muito similar.

A partir de uma construção simbólica referente às imagens cotidianas, foram sendo concebidos os primeiros alfabetos. Era a escrita ideográfica, que remetia o desenho das letras a animais, estações do ano, a agricultura, etc.

Após a descoberta do papel e a invenção da prensa por Gutenberg, em 1450, começou-se a produzir muitos jornais e informativos na Europa e América do Norte. Com o desenvolvimento dos meios de comunicação de massa impressos passou-se a utilizar ilustrações para complementação do conteúdo das notícias e, posteriormente, para contar breves histórias cômicas em tiras:

A evolução da indústria tipográfica e o surgimento de grandes cadeias jornalísticas, fundamentados em uma sólida tradição iconográfica, criaram as condições necessárias para o aparecimento das HQs como meio de comunicação de massa. (Vergueiro, 2010, p.8)

Data de 1895 a primeira História em Quadrinho chamada "The Yellow Kid", produzida por Richard Felton Outcault no jornal New York World de Joseph Pulitzer. Admite-se como a primeira HQ por apresentar os balões de fala, recurso fundamental para a criação de diálogos na Arte Sequencial. Como as histórias quase sempre tinham cunho cômico, em inglês, passaram a chamar-se de Comics (Nerdcetera, 2013). E esse foi um dos motivos pelos quais as HQs foram por muito tempo desacreditadas pela sociedade, tendo seu potencial midiático e educativo reprimido.

Após a evolução das tiras de jornais para as revistas em quadrinhos (Gibis, no Brasil), houve uma grande comercialização de HQs que seguiam com as temáticas cômicas ou abordavam assuntos infanto-juvenis, buscando os públicos que mais consumiam este produto. No entanto, o público adulto e acadêmico não visualizaram que as HQs poderiam ser melhor utilizadas como dispositivos de comunicação, sendo aproveitadas na educação ou para contribuir nos fundamentos culturais de seus leitores.

A partir de 1940, algumas poucas produções traziam cunho educativo mediante a adaptação de histórias da literatura americana e mundial. Revistas como a True Comics, Real Life Comics e Real Fact Comics publicaram histórias de William Shakespeare, Edgar Allan Poe, Victor Hugo, entre outros.

Durante a Segunda Guerra, Will Eisner, famoso quadrinhista da revista "The Spirit", em parceria com o governo norte-americano, produziu uma série de manuais para o treinamento dos combatentes militares. 
Ao findar-se a Segunda Guerra Mundial, estabeleceu-se um ambiente de discórdia generalizada e os quadrinhos passaram a ser atacados e difamados como uma das maiores causas para os problemas juvenis. Fredric Wertham, psicólogo alemão, escreveu "A sedução dos inocentes", livro que argumentava que as HQs incitavam problemas mentais na população jovem dos Estados Unidos. Sua campanha teve repercussão geral, pois a Association of Comics Magazine acabou elaborando uma proposta de código de produção que direcionava as publicações quadrinhísticas, limitando e censurando seu conteúdo para que condissessem com a moral e ética vigente. Como garantia de que a revista de História em Quadrinho tinha qualidade aprovada pela associação, em suas capas eram inseridos selos.

No Brasil, esse Comics Code foi elaborado por um grupo de editoras e também aprovava as publicações colando um selo de qualidade em suas capas. Como conseqüência disso, muitas editoras faliram e houve uma homogeneização dos conteúdos das HQs, distanciando cada vez mais este meio comunicativo de um possível uso nas escolas de maneira legitimada pela sociedade.

$\mathrm{Na}$ China comunista, na década de 50, Mao Tse-Tung fez uso das HQs para moldar um novo pensamento cidadão, em seu país. As tiras traziam exemplos de moral e ética numa promoção de bons costumes, exaltando um novo exemplo de vida para a sociedade.

A utilização das Histórias em Quadrinhos em publicações didáticas começou a se dar de forma gradativa na Europa dos anos 70. As ilustrações foram aos poucos sendo utilizadas em materiais de suporte educacional e de acordo com a sua aceitação, novas experimentações foram feitas. Diversas editoras produziram volumes de Enciclopédias no formato de quadrinhos e suas vendas foram demonstrando que este meio de comunicação estava sendo aceito novamente:

Mais recentemente, em muitos países, os próprios órgãos oficiais de educação passaram a reconhecer a importância de se inserir as histórias em quadrinhos no currículo escolar, desenvolvendo orientações específicas para isso. (Vergueiro, 2010, p.21)

Há anos o uso das HQs foi reconhecido pela Lei de Diretrizes e Bases (LDB) e pelos Parâmetros Curriculares Nacionais do Brasil, permitindo o uso das histórias em quadrinhos para fins didáticos.

\section{Opções metodológicas}


Como as oficinas do programa EDUCOM UFSM seguem os princípios educomunicacionais como forma de emancipação crítica e social dos jovens estudantes, definimos como metodologia de pesquisa alguns parâmetros de estudo, embasando e norteando as atividades do curso.

Vergueiro (2010) propõe um modelo estrutural que divide a pesquisa de HQs em quatro aspectos: Enfoque, Foco, Método e Técnica. Enfoque é a visão predominante da pesquisa, o ponto de vista principal por onde o estudioso partirá. Como conseqüência do enfoque, tem-se o Foco, que se relaciona diretamente com o objeto de estudo da pesquisa. O Método é um conjunto de procedimentos e meios utilizados para se encontrar uma conclusão ou finalidade a cerca de um determinado assunto. Por fim, a Técnica desenvolvida dependerá das relações prévias feitas entre os três aspectos anteriores.

Este estudo tem seu Enfoque na Aplicação das HQs em salas de aula; seu Foco é o processo de aprendizado da linguagem dos quadrinhos; seu Método é o hipotéticoindutivo:

defende a necessidade de formulação de hipóteses quando "os conhecimentos disponíveis sobre determinado assunto são insuficientes para a explicação de um fenômeno (Gil, 1999, p.30 apud Vergueiro, 2010, pp.198).

Por fim, a pesquisa experimental, na opinião do autor, é a principal técnica quando o enfoque for a aplicação.

Abaixo, o modelo estrutural para a pesquisa de HQs proposto por Vergueiro (2010, pp.198): 
Tabela 1. Aspectos metodológicos para a pesquisa sobre Histórias em Quadrinhos

\begin{tabular}{|c|c|c|c|}
\hline ENFOQUE & FOCO & MÉTODO & TÉCNICA \\
\hline No produto cultural & Mensagem & Semiótico & $\begin{array}{c}\text { Análise de } \\
\text { conteúdo; } \\
\text { Análise semiótica; } \\
\text { Análise do discurso; } \\
\text { Análise documental. }\end{array}$ \\
\hline Na produção & $\begin{array}{l}\text { Produtor; } \\
\text { Aspectos } \\
\text { econômicos e } \\
\text { mercadológicos; } \\
\text { Criação; } \\
\text { História. }\end{array}$ & Indutivo & $\begin{array}{c}\text { Entrevista em } \\
\text { profundidade; } \\
\text { Pesquisa } \\
\text { documental; } \\
\text { Estudo de caso; } \\
\text { Análise de } \\
\text { conjuntura. }\end{array}$ \\
\hline Na recepção & $\begin{array}{c}\text { Impactos } \\
\text { psicológicos e } \\
\text { sociais no público } \\
\text { leitor }\end{array}$ & Dedutivo & $\begin{array}{c}\text { Estudo de } \\
\text { audiência; } \\
\text { Grupo focal; } \\
\text { Questionários e } \\
\text { escalas de atitudes. }\end{array}$ \\
\hline Na aplicação & Processo & Hipotético-dedutivo & $\begin{array}{c}\text { Pesquisa } \\
\text { experimental }\end{array}$ \\
\hline
\end{tabular}

\section{Uso das HQS na sala de aula}

A inserção das histórias em quadrinhos no macrocampo da comunicação do Programa Mais Educação (MEC Brasil) demonstra uma abertura para novas formas de ensino, utilizando-se de recursos que aproximem os alunos dos conteúdos trabalhados em aula. Mas de que forma as histórias em quadrinhos fazem essa aproximação? Quais são as características que qualificam esta mídia a ser utilizada em salas de aula? O que faz os alunos se interessarem por gibis e usá-los para a sua formação educativa?

O Enem (Exame Nacional do Ensino Médio), prova que vem sendo aplicada desde 2009 como forma de acesso às universidades brasileiras, já avalia a capacidade interpretativa das diferentes linguagens verbais e não-verbais dos estudantes, dando valor a uma alfabetização imagética além da já trabalhada educação textual. Um dos grandes potenciais das histórias em quadrinhos advém de sua estrutura, que é: 
Uma linguagem que articula três códigos distintos (o visual, através dos quadros; o esquemático, através da articulação entre os quadros; e o verbal, não obrigatório, vale lembrar, através dos textos das personagens e/ou dos narradores) permite, por um lado, uma série de possibilidades combinatórias e variações, a partir do arranjo desses três códigos. (Moll, s.d., p.62)

A utilização conjunta de palavras e imagens reforça de maneira complementar as possibilidades de absorção das informações a serem transmitidas, dando aos gibis poder de "criação de um novo nível de comunicação, que amplia a possibilidades de compreensão do conteúdo programático por parte dos alunos" (Vergueiro, 2010, p.22).

Por ser uma linguagem que desde o seu cerne foi bem aceita pelo público infantojuvenil, independente das temáticas tratadas, os estudantes demonstram muita vontade em ler HQs, quanto mais produzi-las. Desta forma, a tomada de consciência e absorção dos conteúdos programáticos pode se dar de forma mais leve, na linguagem do próprio aluno, evitando a perda de concentração deste e as longas explanações dos professores. Ou seja, o uso das histórias em quadrinhos pode servir como aparato motivador para o desenvolvimento crítico e formação educacional dos jovens estudantes curiosos por conhecer essa arte.

Com a alfabetização imagética e conhecimento da linguagem dos quadrinhos no decorrer dos encontros nas escolas, os estudantes passam a se interessam mais pela leitura. As HQs não substituem os livros, mas possibilitam acesso a grande quantidade de informação. Elas adaptam o conhecimento a sua linguagem concebendo a visualização de textos verbais, e às vezes, de textos subliminares ou sugeridos.

Ainda com base no autor, com a seleção de momentos-chave para apresentação nos quadrinhos da história, o leitor faz um movimento imaginativo para formular em sua mente as conexões necessárias para que a narrativa se complete. $\mathrm{O}$ ato de preencher mentalmente as lacunas da história é chamado de elipse. O movimento elíptico que os gibis sugerem, possibilita o contínuo exercício imaginativo para os estudantes, auxiliando-os no desenvolvimento desta habilidade.

Há de se tomar cuidado com alguns equívocos que geralmente surgem durante as atividades. A produção de uma $\mathrm{HQ}$ não demanda o mesmo tempo que a sua leitura. Não é necessário saber ou ter uma técnica aguçada de desenho, pois para se produzir uma história em quadrinho é necessário apenas um roteiro e um esboço visual, um croqui.

Os quadrinhos podem ser produzidos com baixíssimo custo e promovem a produção colaborativa entre os alunos, podendo ser utilizadas nos diversos níveis escolares e 
como suporte para as disciplinas. É possível desempenhar funções individualmente ou em grupo, formando equipes de roteiristas, desenhistas, revisores, arte-finalistas, coloristas, letreiristas, etc.

As produções no ambiente escolar incentivam a observação da comunidade e diversas concepções e representações deste universo, sem contar na acessibilidade que está intrínseca.

Não existem limitações para o uso das HQs em sala de aula a não ser a criatividade e dedicação do professor ou ministrante de uma oficina e também dos alunos. Quanto mais envolvidos no processo melhor será o desenvolvimento individual e coletivo (Vergueiro, 2010, p.26).

\section{Oficina de HQs no projeto EDUCOM UFSM desenvolvida na Escola Augusto Ruschi}

Fundamentada em uma pesquisa bibliográfica especifica sobre Histórias em Quadrinhos em sala de aula, a oficina de HQs do projeto EDUCOM UFSM foi pensada de maneira a adaptar-se aos diversos desafios, condicionamentos e contextos que se apresentam ao longo do projeto e do ano de 2013. O caráter adaptativo da oficina é instigado desde o seu cerne e intrínseco a própria mídia, que apresenta alto grau de adaptabilidade como sistema comercial, acadêmico e funcional, na transmissão de conhecimentos e interatividade dos leitores.

Seus recursos verbais e não-verbais, o contínuo ato elíptico e a possibilidade de uso como sistema midiático comunicacional dão as HQs potencialidade pedagógica, uma vez que, dentro do sistema educacional tradicional existe dificuldade de manter a concentração dos alunos.

A oficina, inicialmente, foi ministrada aos alunos de primeiros e segundos anos do ensino médio, sendo de cunho teórico-prático. Em um primeiro momento, a partir da apresentação dos conteúdos estudados e analisados previamente pelo ministrante da oficina, foram fomentados os debates entre alunos. As exposições foram feitas utilizando-se de recursos audiovisuais disponíveis na escola: Power Point, vídeos e material impresso.

Através da mediação do oficineiro, foram propostas atividades que exercitam o aprofundamento dos temas trabalhados. Identifica-se as necessidades e dificuldades do grupo e direciona-se os exercícios de forma a sanar tais problemas. Alguns dos exercícios práticos são feitos individualmente, de maneira a prover a todos os alunos, conhecimento sobre o tema em questão. No entanto, de acordo com o exercício, os 
alunos trabalham em grupos formados desde o primeiro encontro, com o intuito de produzir Histórias em Quadrinhos coletivamente (do roteiro escrito à arte finalizada). Todos trabalham nas funções segmentadas da cadeia produtiva de uma $\mathrm{HQ}$ e tem a oportunidade de se especializar nas áreas com as quais mais se identificam.

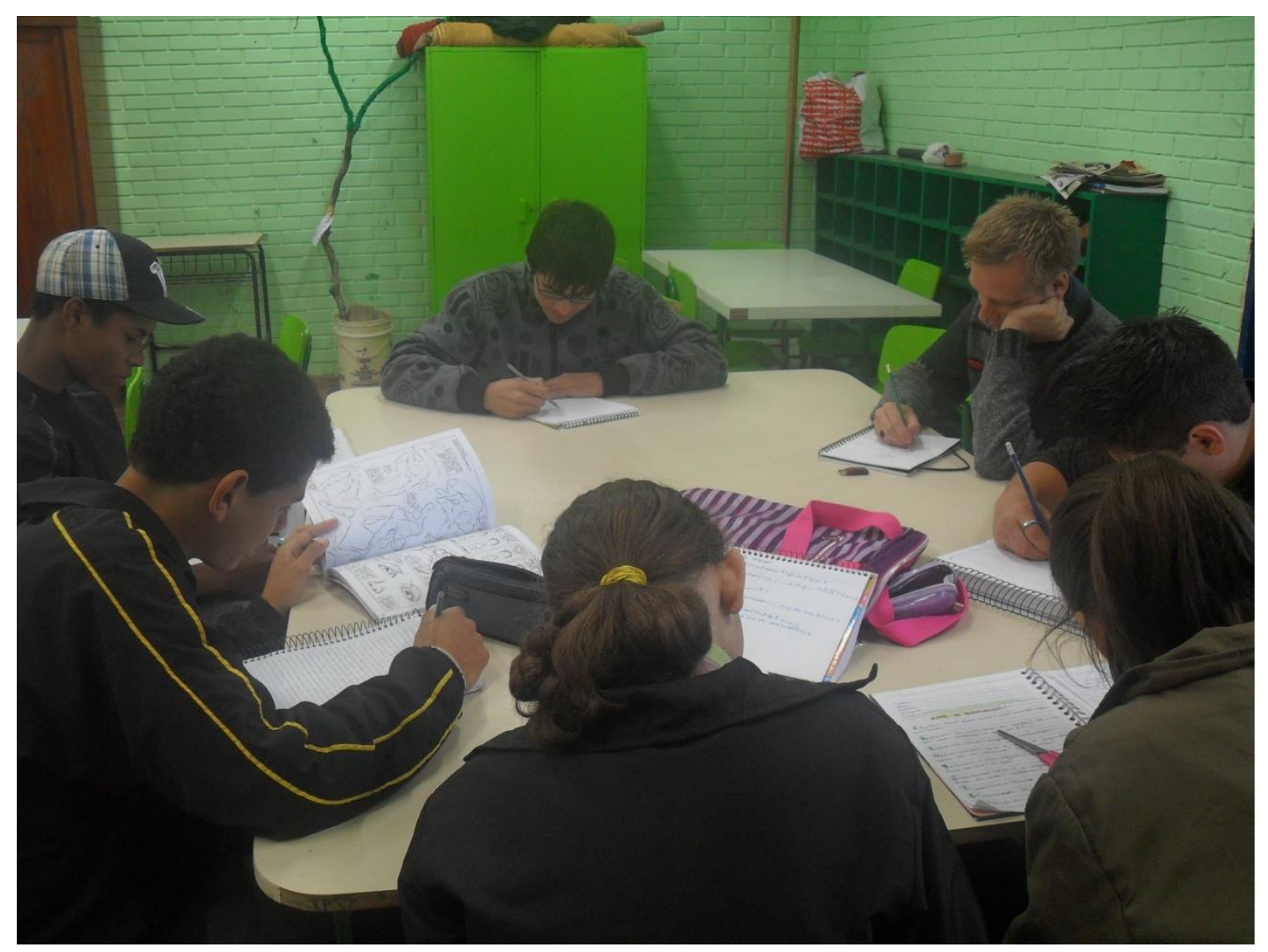

Imagem 2: roteirização durante a oficina na Escola Augusto Ruschi. Fonte: Elaboração própria.

Em cada encontro foi abordado uma temática dos quadrinhos que norteou as atividades e debates. Tendo em vista que são oito encontros e a ideia principal do projeto EDUCOM UFSM é valorizar o processo de desenvolvimento crítico e cidadão dos alunos e formar multiplicadores de conhecimento, os encontros são divididos de forma a apresentar as principais características das HQs, dar uma noção de como funciona a cadeia produtiva de uma revista de histórias em quadrinhos, bem como exercícios práticos. 
A oficina de Histórias em Quadrinhos teve seus primeiros encontros na Escola Estadual de Ensino Fundamental e Médio Augusto Ruschi. Previamente o oficineiro conversou com os professores encarregados do programa na escola para definir a utilização da infra-estrutura escolar e número de alunos que poderiam participar. Durante uma semana as professoras divulgaram a oficina para seus alunos. A oficina começou no dia 06/05/13 com duas turmas de 14 alunos e findou-se no dia 13/07/2013, com uma turma fixa de 10 alunos, com dois encontros semanais. A cada encontro alguns exercícios eram utilizados para sensibilização da linguagem dos quadrinhos e a introdução dos alunos às técnicas e a cadeia de produção de gibis. Ao findar os oito encontros, a escola ofertou mais algumas semanas de oficina para que os alunos pudessem ter tempo de produzir uma revista de Histórias em Quadrinhos autorais originais, baseadas nos exercícios propostos durante a oficina.

\section{Encontro 1. Educomunicação, apresentação das aulas e método}

O primeiro encontro foi destinado a apresentação da oficina e da metodologia educomunicativa. Houve um momento para uma conversa informal com os alunos, com a finalidade de compreender o contexto, a realidade da comunidade e da escola, as dificuldades técnicas e as habilidades individuais. Foi um momento para criar uma conexão com os alunos e estabelecer um bom vínculo de trabalho. O objetivo foi adaptar a oficina, desde o início dos encontros a realidade dos estudantes:

Os planejamentos desenvolvidos pelos oficineiros e educomunicadores procuram iniciar uma conversa aberta na sala de aula. O objetivo principal dos primeiros momentos é conquistar um espaço de confiança entre todos os integrantes. Esse processo é importante porque garante a entrega e a sinceridade com o qual os debates, as críticas e as propostas práticas serão trabalhados. (PNM, s.d., p.20)

No final do primeiro encontro foi proposto um exercício prático, no qual os alunos já começaram a desenhar e a entrar em contato com as possibilidades de produção de HQs, a partir do Exercício no 6 - Escolha de imagens, proposto por McCloud, (2008, p.57)

Teste sua memória visual. Tente fazer de memória um desenho simples de cinco itens complexos (por exemplo: um hidrante, seu arranha-céu favorito, uma tesoura, um tênis, um controle de vídeo-game...). Então verifique o objeto real ou procure fotos na web. Estude as diferenças. Em seguida, desenhe os mesmos itens uma vez mais de memória e veja se você o reproduziu mais efetivamente. 
Embora desenhar de memória não seja tão necessário hoje como era em minha geração (é possível encontrar fotos de praticamente qualquer coisa on-line), essa prática pode ajudar a isolar os detalhes estruturais mais importantes dos objetos, e estes podem ativar a memória dos leitores sem sobrecarregá-los com detalhes desnecessários.

\section{Encontro 2. Formato, leitura e linguagem e cadeia produtiva das HQs}

O segundo encontro voltou-se para a apresentação da história das HQs, seus múltiplos formatos (gibis, graphic novels, HQtronicas, etc.), características principais e a cadeia produtiva.

Foi abordado o conjunto de elementos que constroem a linguagem das $\mathrm{HQs}$ e a forma em que se relacionam. Como é a leitura de uma $H Q$ ? Para que servem os balões de texto? O que acontece entre um quadrinho e outro?

Num segundo momento, foi discutido de que forma as revistas de histórias em quadrinhos são produzidas. Foram apresentadas diversas HQs para que todos tomem conhecimento do que está sendo tratado. Foram utilizados recursos audiovisuais para fomentar o debate e promover os exercícios práticos.

Durante a oficina do Ruschi, os alunos tiveram acesso a alguns gibis para uma breve leitura e tomada de consciência dos assuntos expostos pelo oficineiro. Após esse contato, fomos para o pátio da escola para um exercício:

Exercício no 10 - Exercícios para destravar

Quanto Comics (invenção dos lendários irmãos Dewan, Ted e Brian). Junte-se a um ou mais amigos quadrinhistas. Arrume alguns marcadores pretos e papel em branco. Cada artista passa uns poucos minutos desenhando um título no topo de uma página (os títulos devem ser coisas gerais, como "Esse é seu pai?", "Namoro as cegas", "Ignore e passará", fechado às segundas" etc. Evite coisas específicas demais, como "O Papa Bento e o Jamiroquai foram saltar de pára-quedas na Pensilvânia". Os artistas em seguida trocam as folhas e desenham uma história de uma página correspondendo ao título de alguém. Repita até bater o sono. (McCloud, 2008, p.57)

\section{Encontro 3. Técnicas de desenho e formas de contar-se uma história}


Neste encontro serão abordadas algumas das técnicas de desenho mais utilizadas na produção de histórias em quadrinhos, como o uso da caneta nanquim para artefinalizar, técnicas de desenho com grafite $6 \mathrm{~B}$, entre outros. $\mathrm{O}$ encontro também possibilitará experienciações com fotografia e outras formas de se contar uma história através de imagens.
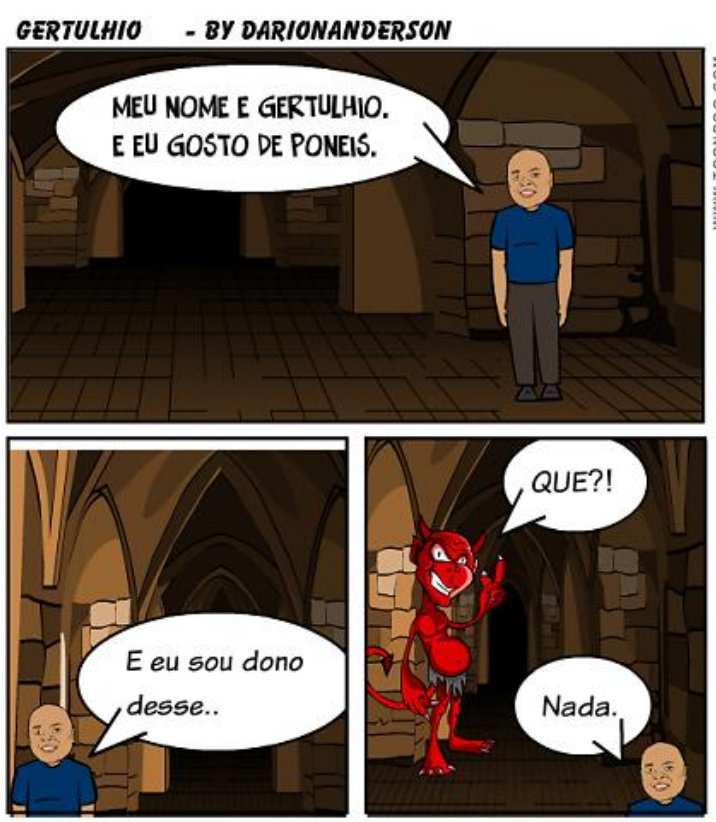

Imagem 3: História em Quadrinhos Web dos alunos da oficina da Escola Augusto Ruschi. Fonte: Alunos A. Ruschi.

Na escola A. Ruschi, após a explanação do oficineiro, sobre técnicas de persuasão visual e formas de contar uma história visualmente, foram propostas pelos próprios alunos, duas atividades: a produção de uma $\mathrm{HQ}$ na internet (para exercitar as habilidades de estruturar espaços gráficos) e uma fotonovela (com o intuito de colocar em prática o aprendizado de ângulos e planos de câmera).

\section{Encontro 4. Criação dos personagens}

No quarto encontro, a temática foi a construção de personagens para as histórias em quadrinhos. Como os personagens são fisicamente? Qual é a história deles? Quais são os objetivos de vida destes personagens? Quais são os seus gostos? Alguns exemplos são dados e a partir disso serão feitos exercícios para fixar o conteúdo. 
$\mathrm{Na}$ Augusto Ruschi, começamos a preparar os personagens para adentrarem nas histórias autorais, que viriam a fazer parte da revista "Traços do Futuro", produzida pelos próprios alunos. Fizemos alguns exercícios para salientar a importância da construção do personagem para a fundamentação de uma boa $\mathrm{HQ}$ :

Exercício no 1 - História da vida de um personagem

"Considere sua própria história e como ela moldou você". Tente listar os cinco aspectos mais importantes de sua própria história. Sua vida familiar, seu local de nascimento, grandes acontecimentos etc. Em seguida, cie um novo personagem que não se pareça em nada com você, mas que tenha tido essas mesmas experiências em seu passado. Considere que tipo de pessoa teria emergido dessa história.

Agora crie um segundo personagem com uma história de vida oposta nesses mesmos cinco sentidos. Como os dois se relacionam caso as circunstancias os aproximassem?

Exercício ํㅡ 2 - Lançando uma rede ampla

Crie um elenco de três a cinco personagens, todos diferentes em pelo menos quatro dos seguintes aspectos, mas iguais em todos os demais. Como suas diferenças ajudariam a destacar aquilo que eles todos têm em comum?

- Peso

- Perfil facial

- Altura

- Beleza

- Força

- Raça e etnia

- Histórico

- Desejos

(McCloud, 2008, p.127)
- Idade

- Inteligência

- Estilo de

roupas

- Temperamento

- Obrigações

- Devotamento

- Sexo

\section{Encontro 5. As palavras nas HQs}

No quinto encontro, após terem sido desenvolvidos os personagens, foi abordada a temática da roteirização. Como se constrói um roteiro de HQ? Como se faz um 
esboço de roteiro? É preciso desenhar perfeitamente? Os grupos se juntarão e debaterão sobre que assunto que irão tratar em suas HQs.

$\mathrm{Na}$ oficina de HQs da escola Ruschi, tivemos a participação da oficineira de audiovisual do programa EDUCOM UFSM, Cristini F. Fernandes, que explanou sobre roteirização e indicou aos alunos algumas sugestões de temáticas a serem escritas para a produção da revista "Traços do Futuro".

\section{Encontro 6. Criação de universos}

No sexto encontro os participantes tomaram conhecimento sobre como ambientar uma história e pensar seus cenários. Uma parte da oficina foi ministrada fora da sala de aula, no pátio, para que os estudantes observassem e desenhassem o mundo ao seu redor:

\section{Exercício no 3 - Aqui está você}

Onde quer que esteja agora, observe o ambiente à sua volta. Enumere nove aspectos dele: visões, sons, cheiros, texturas, etc. Crie uma seqüência panorâmica de página única em nove quadrinhos capaz de evocar todas essas qualidades para o leitor.

Versão alternativa: tire fotos do que você vê ao seu redor e escolha as nove que melhor representem o ambiente e as várias sensações que você associa a ele.

(McCloud, 2008, p.57)

\section{Encontro 7. Encontro com convidado e finalização de HQs}

O sétimo encontro foi reservado para uma conversa com um profissional a ser convidado pelo ministrante da oficina, para que os estudantes obtenham noções de como as HQs são feitas profissionalmente. Após a discussão, o convidado participou das atividades práticas conjuntamente aos alunos, auxiliando-os em seus projetos.

Na Augusto Ruschi, esse sétimo encontro se estendeu por mais algumas semanas, pois a oficina ganhou mais tempo para a produção da revista em quadrinhos "Traços do Futuro".

\section{Encontro 8. Apresentação do projeto final e evento de lançamento}


Planejou-se, em conjunto, um evento de lançamento de uma fanzine para o ultimo encontro da oficina de Histórias em Quadrinhos EDUCOM UFSM. Foram propostas atividades diversas como: uma mini-feira para divulgação das Histórias em Quadrinhos, encontros com profissionais da área e com estudantes e produção e posterior lançamento de uma revista para distribuição entre as escolas integrantes do Programa EDUCOM UFSM, conjuntamente a oficina de fanzines:

Deve-se buscar a integração dos quadrinhos a outras produções das indústrias editorial, televisiva, radiofônica, cinematográfica, etc. tratando todos como formas complementares e não como inimigas ou adversárias na atenção dos estudantes. (Vergueiro, 2010, p.27)

Com a turma motivada e engajada foi viabilizado o evento de lançamento da revista fanzine "Traços do Futuro", com uma surpresa revolucionária para os padrões educacionais vigentes, porém muito agradável. Os alunos sugeriram que, durante o evento de lançamento da revista, eles desenhassem uma História em Quadrinhos utilizando-se de mesas de sala de aula. Cada mesa era um quadrinho de uma história maior chamada "Um ato de liberdade", que contava como foi o processo de aprendizado da oficina. Com essa atitude, os alunos conquistaram o professorado, que os incentivou, fornecendo a estrutura escolar. No dia 13 de Julho de 2013, 9 alunos de $1^{\circ}$ e $2^{\circ}$ anos do Ensino Médio e mais um aluno do $6^{\circ}$ ano do Ensino Fundamental desenharam em classes de aula, enquanto seus pais e professores os observavam atentamente a cada movimento de mão que ia construindo um desenho e uma história.

$\mathrm{Na}$ semana subseqüente, o oficineiro e os alunos foram convidados a ministrarem uma oficina de capacitação para os professores da Escola Augusto Ruschi. Houve uma inversão de papéis, pois os alunos se tornaram os monitores de seus professores, e seus professores, alunos. Uma experiência impar à ambos.

Abaixo a revista produzida pelos alunos durante os encontros da oficina. 


\section{TRACSOS DO} FUTURO

\section{Uma $A Q$ Educomunicativa}

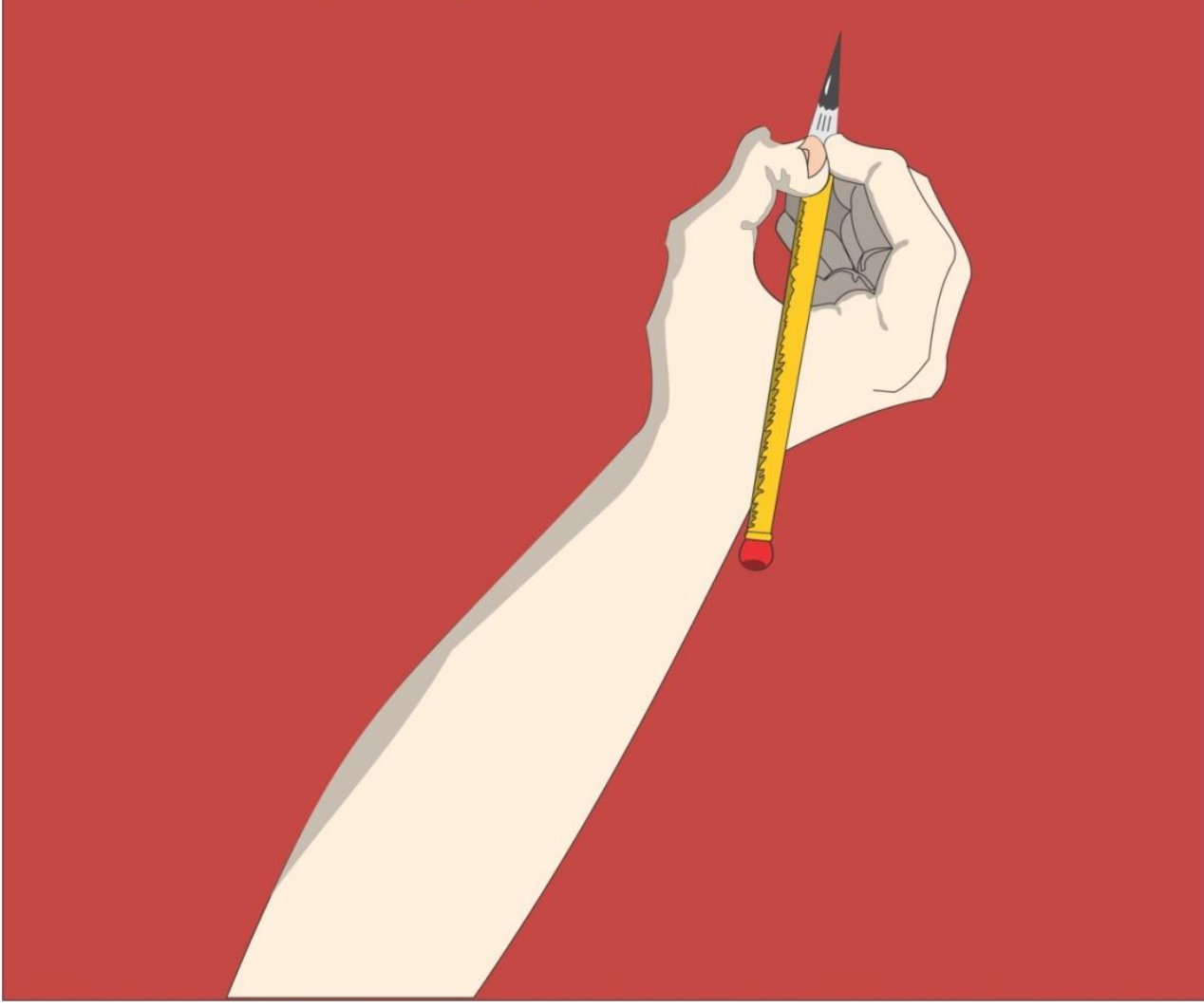

Imagem 8: capa da revista fanzine "Traços do Futuro", produzida durante a oficina da Escola Augusto Ruschi. Fonte: Elaboração própria. 


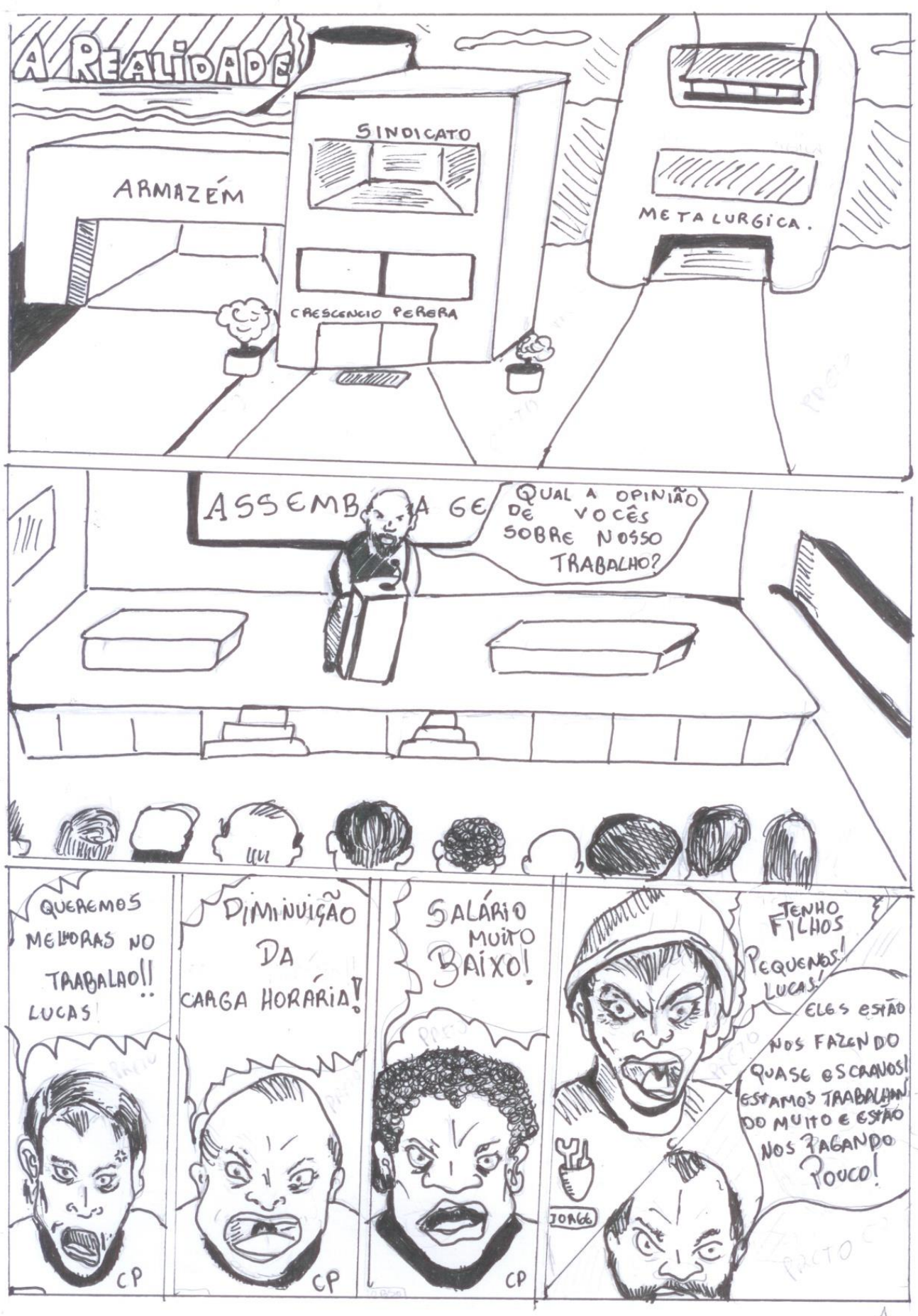

Imagem 9: primeira página da $H Q$ "A Realidade", da revista fanzine "Traços do Futuro". Fonte: Alunos A. Ruschi. 

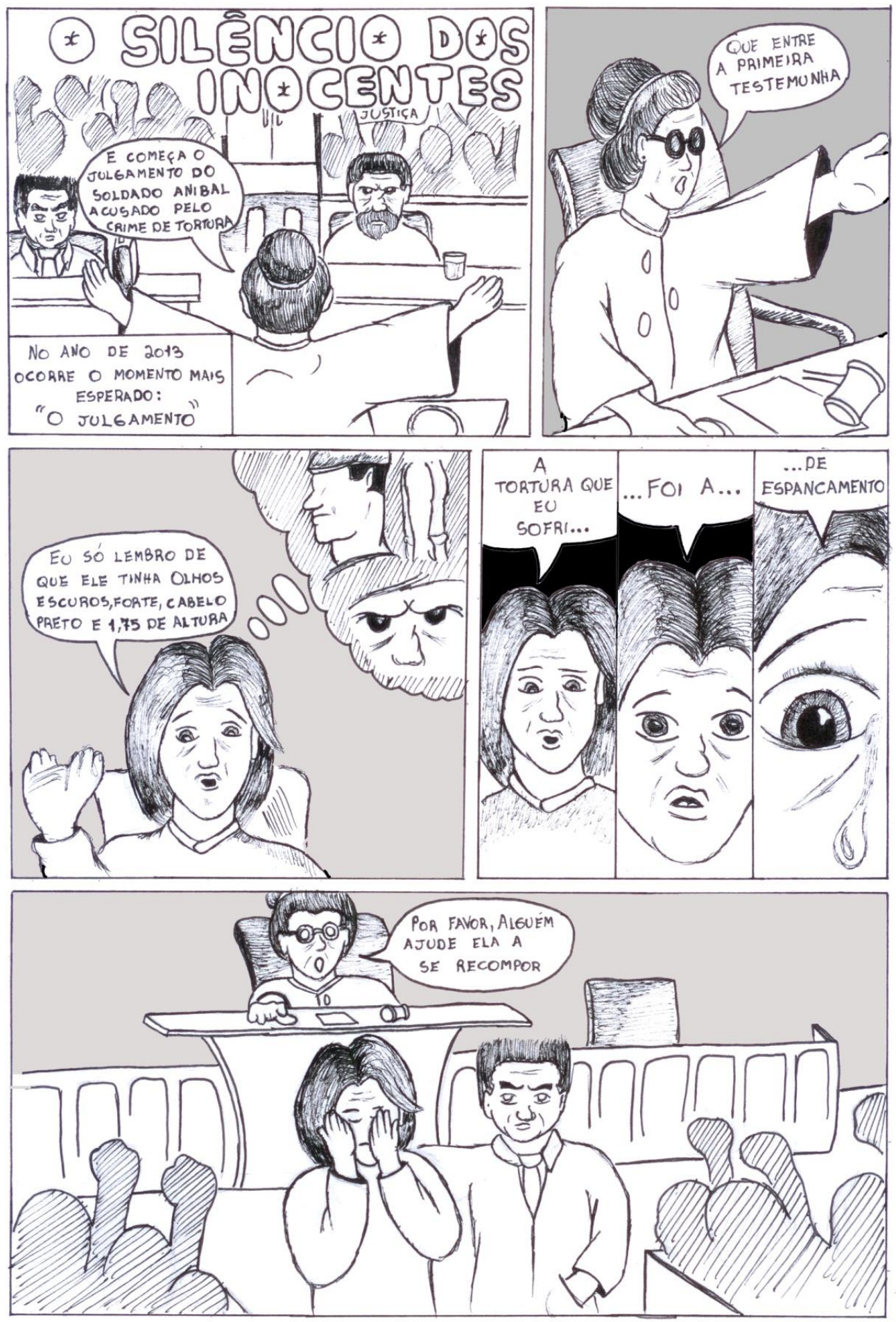

Imagem 10: primeira página da $\mathrm{HQ}$ "O Silêncio dos Inocentes", da revista fanzine "Traços do Futuro". Fonte: Alunos A. Ruschi. 


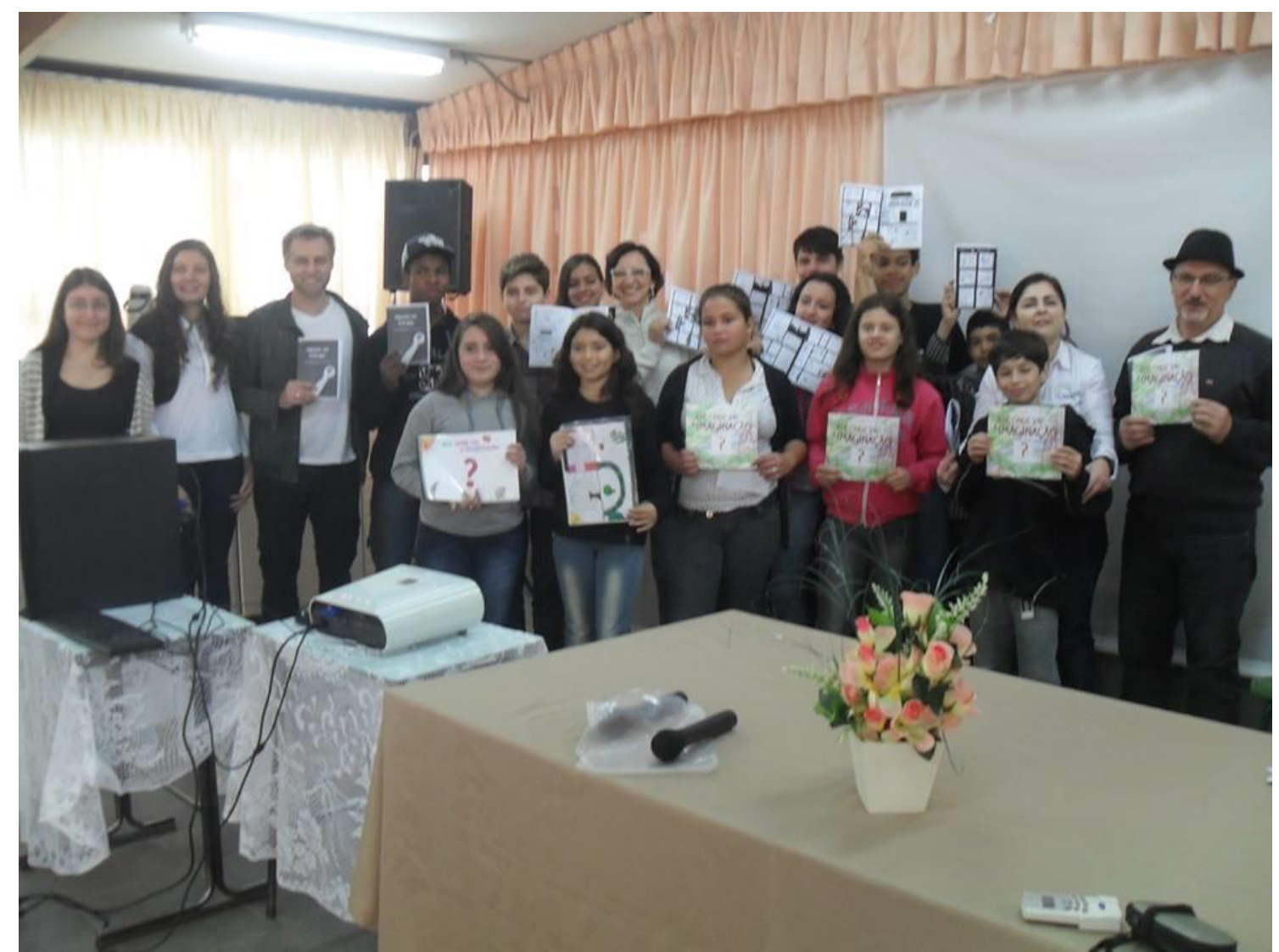

Imagem 11: Evento de lançamento da revista "Traços do Futuro".

\section{BIBLIOGRAFIA}

McCloud, S. (2008). Desenhando Quadrinhos: os segredos das narrativas de quadrinhos, mangás e graphic novels. São Paulo: M. Books.

Moll, J. (Org.) (s.d.). Cadernos Pedagógicos Mais Educação: Comunicação e Uso de Mídias. Acessado em 04 de Maio de 2013 em: http://portal.mec.gov.br/index.php?option=com docman\&task=doc download\&gid= $\underline{12328 \& \text { Itemid }=}$

Nerdcetera. (2013). CeteraComics \#01 - A História das Histórias em Quadrinho!. Acessado em 04 de Maio de 2013 em: https://www.youtube.com/watch?v=dLuwFJB7Vgo

Projeto Nossa Mídia (s.d.). Educomunicação. Curitiba: Universidade Federal do Paraná. 
Vergueiro, W. (2004). Como usar as Histórias em Quadrinhos na sala de aula. In Angela Rama e Waldomiro Vergueiro (Org.), Uso das HQs no ensino (pp. 07-30). São Paulo: Contexto.

Vergueiro, W. (2010). Pesquisa empírica em Comunicação. In José Luiz Braga, Maria Immacolata Vassallo de Lopez, Luiz Cláudio Martino (Org.), Para uma metodologia da pesquisa em Histórias em Quadrinhos (pp.183-203). São Paulo: Paulus.

Santos, M. E. et al. (s.d.). Programa Mais Educação Passo-a-passo. Acessado em 04 de Maio de 2013 em: http://portal.mec.gov.br/dmdocuments/passoapasso maiseducacao.pdf

\section{Agradecimientos}

Programa "Educomunicação e Cidadania Comunicativa", desenvolvido pela Universidade Federal de Santa Maria de fevereiro a dezembro de 2013, pelo edital $n^{\circ} 1 / 2012$;

Universidade Federal de Santa Maria;

Coordenação de Aperfeiçoamento de Pessoal de Nível Superior (CAPES); Ministério da Educação (MEC).

\section{Forma de citar este artículo en bibliografías}

DENIS LUCAS, H.; ROSA, R. Y FERNANDES, C (2013): "História em quadrinhos: reflexões metodológicas" en Revista PANGEA, 4, páginas 190 a 204. Red Académica Iberoamericana de Comunicación. Recuperado el de de 2 de: http://www.revistapangea.org 